\title{
Arterite de Takayasu e Arterite Temporal (Arterite de Células Gigantes)
}

\section{Takayasu's Arteritis and Giant Cell Arteritis}

\author{
Boris Afonso Cruz ${ }^{1}$
}

\begin{abstract}
A arterite de células gigantes (ou arterite temporal) é uma forma de vasculite relativamente comum em idosos, que acomete preferencialmente artérias de maior calibre, especialmente as artérias temporais, carótidas, vertebrais e a aorta. A arterite de Takayasu também se caracteriza pelo envolvimento de artérias de maior calibre, notadamente através de lesões inflamatórias estenóticas da aorta e seus ramos primários. Em contraste à arterite de células gigantes, a arterite de Takayasu afeta preferencialmente mulheres jovens.

Ainda que sejam duas formas diferentes de vasculite, a arterite de Takayasu e a arterite de células gigantes têm características clínicas semelhantes, como o tamanho e a distribuição dos vasos acometidos, sintomas isquêmicos conseqüentes à estenose vascular com proliferação intimal, boa resposta ao corticóide e etiologia indefinida, com aspectos sugestivos de auto-imunidade celular como principal mecanismo fisiopatogênico. Outro aspecto comum é gravidade potencial que se associa à progressão das doenças e o desafio prático que seu tratamento crônico representa. Neste número da Revista Brasileira de Reumatologia, esta sessão apresenta publicações recentes que discutem diferentes formas de tratamento dessas condições clínicas.
\end{abstract}

Maksimowicz-McKinnon K, Clark TM e Hoffman GS. Limitations of Therapy and a Guarded Prognosis in an american Cohort of Takayasu Arteritis Patients (Limitações da terapia e prognóstico reservado em uma coorte americana de pacientes com arterite de Takayasu). Arthritis Rheum 56:1000-9, 2007. Cleveland Clinic Foundation, Center for Vasculitis Care and Research, Cleveland/EUA.

Nesta publicação, os autores descrevem aspectos clínicos, laboratoriais e progressão das alterações vasculares nos exames de imagem de uma série de pacientes com arterite de Takayasu $(\mathrm{n}=75)$, avaliados em um serviço de referência, em um protocolo padronizado de propedêutica e tratamento. Desses pacientes, 30 foram seguidos prospectivamente no serviço (média de 3 anos; de 4 meses a 10 anos) e para estes são apresentados dados de evolução e prognóstico. No que diz respeito à terapêutica, o tratamento inicial incluía prednisona $(1 \mathrm{mg} / \mathrm{kg} / \mathrm{dia})$ por 4 semanas, com redução progressiva até sua suspensão ou recidiva. Quando da recidiva, a dose diária de prednisona era aumentada em $10 \mathrm{mg}$ e metotrexato era adicionado ao esquema terapêutico, inicialmente na dose de $15 \mathrm{mg} /$ semana, com incremento até $25 \mathrm{mg} / \mathrm{semana}$ de acordo com a necessidade e/ou a tolerância dos pacientes. Em caso de intolerância ou não-resposta ao metotrexato, o paciente recebia azatioprina $(2 \mathrm{mg} / \mathrm{kg} /$ dia, até o máximo de $150 \mathrm{mg}$ /dia). Em caso de não-resposta ou intolerância à azatioprina, micofenolato mofetil era prescrito, na dose de $1,5 \mathrm{~g}$ duas vezes ao dia. Em situações ameaçadoras à vida, ciclofosfamida oral $(2 \mathrm{mg} / \mathrm{kg} /$ dia $)$ fora utilizada. A terapia anti-TNF foi utilizada como terapia experimental em pacientes que não sustentaram remissão com os esquemas terapêuticos previamente descritos. Vinte oito (28\%) dos 30 pacientes seguidos prospectivamente alcançaram remissão em algum momento. A maioria (73\%) necessitou de imunossupressores que incluíram: metotrexato (43\%), anti-TNF (37\%), ciclofosfamida (13\%), azatioprina (7\%) e micofenolato mofetil ( $7 \%)$. No entanto, seis pacientes $(20 \%)$ alcançaram remissão apenas com uso de corticóide e dois pacientes já apresentavam doença inativa quando do início

1. Departamento de Reumatologia - Biocor Instituto.

Endereço para correspondência: Boris Afonso Cruz, Rua Fernandes Tourinho, 999, sala 107, 30112-000, Belo Horizonte, MG, e-mail: boriscruz@terra.com.br 
do seguimento e não fizeram uso de qualquer medicação. Remissão sustentada - definida como ausência de manifestações clínicas, alterações laboratoriais ou progressão das lesões vasculares por $\geq 6$ meses em uso de dose de prednisona $\leq 10 \mathrm{mg} /$ dia - foi alcançada em apenas oito de 28 pacientes $(28 \%)$. Recidiva - caracterizada pelo surgimento de sintomas sistêmicos e/ou elevação de provas inflamatórias não explicadas por outra condição clínica, sintomas vasculares novos ou progressão das lesões vasculares - foi documentada em 27 dos 28 pacientes (96\%) que alcançaram remissão (média de 2,83 episódios de recidiva por paciente em um seguimento médio de três anos). A maior parte dos episódios de recidiva ocorreu enquanto os pacientes ainda estavam fazendo uso de imunossupressores. Onze pacientes definidos como refratários receberam terapia anti-TNF. Somente três pacientes apresentaram recidiva quando deste tratamento, mas em dois foi possível alcançar nova remissão com ajuste da dose. Procedimentos de revascularização foram necessários em 21 dos 30 pacientes (70\%) seguidos prospectivamente. Vinte angioplastias (10 delas com stent) foram realizadas. Duas dessas falharam de início e, das 18 que inicialmente se mostraram bem-sucedidas,
14 apresentaram reestenose, levando a novo procedimento em 13 casos. Reconstrução vascular ou bypass foram realizados em 17 pacientes $(57 \%$; 44 procedimentos no total). Reestenose ou oclusão ocorreu em 36\% dos procedimentos. Como desfechos desse seguimento, ocorreram dois óbitos relacionados à doença, ambos em período pós-operatório de pacientes com doença extensa e mais grave. Dezoito pacientes $(60 \%)$ apresentavam claudicação vascular que comprometia as atividades diárias e $23 \%$ se encontravam totalmente incapazes para o trabalho. Mesmo tratando-se de um estudo aberto e com número limitado de pacientes, este trabalho permite algumas inferências práticas. A primeira delas é o fato de a arterite de Takayasu se associar à importante morbimortalidade. O protocolo de tratamento apresentado pelos autores também é uma referência prática de como abordar esses pacientes. Ainda que não sejam dados de ensaios clínicos randomizados, os resultados apresentados sugerem que a terapia anti-TNF pode ser de valia em pacientes que mantém doença ativa a despeito do tratamento e, quando possível, procedimentos cirúrgicos de reconstrução ou bypass devem ser preferidos em relação à angioplastia, por menor risco de falha.

Ozen S, Duzova A, Bakkaloglu A, Bilginer Y, Cil BE, Demircin M, Davin JC, Bakkaloglu M. Takayasu arteritis in children: preliminary experience with cyclophosphamide induction and corticosteroids followed by methotrexate (Arterite de Takayasu em crianças: experiência preliminar com indução com ciclofosfamida e corticosteróides, seguida de metotrexato). J Pediatrics 150(1):72-6, 2007. Departamento de Pediatria, Hacettepe University Faculty of Medicine, Ankara/Turquia.

Neste relato, os autores sugerem um protocolo de abordagem da arterite de Takayasu em crianças estratificado pela extensão da doença. As crianças com doença limitada a um lado do diafragma, desde que não houvesse envolvimento da artéria pulmonar, recebiam corticóides e metotrexato. Por outro lado, as crianças com doença mais extensa recebiam indução com corticóides e ciclofosfamida oral, seguida de metotrexato. Seis crianças (quatro meninas e dois meninos) foram estudadas. Dois pacientes apresentavam doença limitada e foram tratados com corticóides e metotrexato. Quatro pacientes apresentavam doença difusa. Um deles faleceu ainda no primeiro mês da doença por vasculite pulmonar. Os outros três pacientes que receberam ciclofosfamida evoluíram com remissão, ainda que procedimentos vasculares, como bypass da aorta, aorto-renal e mesmo nefrectomia unilateral tenham sido realizados. Os autores entendem que a ciclofosfamida como indução de remissão em crianças com arterite de Takayasu pode ser de valia quando de doença mais extensa.

Shinjo SK, Pereira RM, Tizziani VA, Radu AS, Levy-Neto M. Mycophenolate mofetil reduces disease activity and steroid dosage in Takayasu arteritis (Micofenolato mofetil reduz a atividade da doença e o uso de corticóide em Arterite de Takayasu). Clin Rheumatol 26(11):1871-5, 2007. Divisão de Reumatologia da Faculdade de Medicina da USP, São Paulo, Brasil.

Neste estudo brasileiro, os autores descrevem sua experiência com micofenolato mofetil em 10 pacientes com arterite de Takayasu em atividade. Cinco desses pacientes já haviam recebido outro imunossupressor previamente (me- 
totrexato em quatro, azatioprina em dois e clorambucil em um). Outros cinco pacientes receberam micofenolato mofetil como primeiro imunossupressor quando de recidiva durante a redução de corticóides. A dose utilizada foi de $2 \mathrm{~g} /$ dia e o seguimento médio foi de 23,3 meses. Um dos pacientes apresentou cefaléia atribuída à droga e deixou o estudo. Os outros nove pacientes apresentaram boa resposta com remissão clínica, redução da dose diária de prednisona $(24,5$ $\pm 17,1$ versus $5,8 \pm 7,8 \mathrm{mg} /$ dia; $\mathrm{p}=0,0019)$ e melhora dos parâmetros laboratoriais de inflamação, como a velocidade de hemossedimentação $(24,7 \pm 15,5$ versus $12,8 \pm 10,8$ $\mathrm{mm} / \mathrm{h} ; \mathrm{p}=0,036)$ e a proteína $\mathrm{C}$ reativa $(24,0 \pm 14,9$ versus $11,2 \pm 10,7 \mathrm{mg} / \mathrm{l} ; \mathrm{p}=0,0167)$. Os autores concluem que o micofenolato mofetil pode reduzir os parâmetros clínicos e laboratoriais da doença, sendo um imunossupressor promissor, principalmente em casos refratários.

Hoffman GS, Merkel PA, Brasington RD, Lenschow DJ, Liang P. Anti-tumor necrosis factor therapy in patients with difficult to treat Takayasu arteritis (Terapia anti-TNF em pacientes com arterite de Takayasu de difícil tratamento). Arthritis Rheum 50(7):2296-304, 2004. Cleveland Clinic Foundation, Center for Vasculitis Care and Research, Cleveland/EUA.

Neste estudo-piloto, os autores selecionaram pacientes com arterite de Takayasu caracterizados de difícil tratamento, seja por necessitarem de doses maiores de corticóides para manter a remissão ou que apresentaram recidivas freqüentes a despeito do tratamento. Quinze pacientes foram incluídos. Em 13 deles, ao menos um agente imunossupressor fora tentado sem sucesso antes. Sete pacientes receberam etanercepte (em três deles subseqüentemente trocado por infliximabe) e oito pacientes receberam desde o início infliximabe. Dez dos 15 pacientes alcançaram remissão completa, sustentada por 1 a 3,3 anos sem corti- cóides. Quatro pacientes alcançaram remissão parcial com redução de ao menos $50 \%$ da dose de corticóides. Apenas um paciente não respondeu ao tratamento. Em nove dos 14 pacientes que responderam, foi necessário aumento da dose do agente anti-TNF para manter a remissão. No período de seguimento, ocorreram duas recidivas quando da tentativa de retirar o agente anti-TNF, mas os pacientes alcançaram novamente remissão quando da reintrodução da droga. Os autores entendem que agentes anti-TNF podem ser de valia em pacientes com arterite de Takayasu não-responsiva a outros agentes imunossupressores.

Mahr AD, Jover JA, Spiera RF, Hernandez-Garcia C, Fernandez-Gutierrez B, LaValley MP, Merkel PA. Adjunctive methotrexate for treatment of giant cell arteritis: an individual patient data meta-analysis (Metotrexato como terapia adjuvante em arterite temporal: uma metanálise dos dados individuais dos pacientes). Vasculitis Center, Faculdade de Medicina da Universidade de Boston, Boston, EUA.

Corticóide é o tratamento de escolha para pacientes com arterite temporal e as diretrizes de tratamento sugerem seu uso por 1 a 2 anos. Ainda que quase a totalidade dos pacientes apresente resposta ao corticóide, efeitos adversos são freqüentes e recidivas são descritas em cerca de $50 \%$ dos pacientes no primeiro ano da doença. Quatro ensaios clínicos randomizados apresentaram resultados conflitantes quanto ao benefício do uso de metotrexato como terapia adjuvante em arterite temporal. Neste estudo, os autores analisaram em conjunto os bancos de dados dos três maiores estudos prévios (um dos quatro estudos citados acima incluía não só arterite temporal, mas também polimialgia reumática e os dados não estavam mais disponíveis para análise). Em conjunto, o banco de dados incluiu 161 pacientes, sendo que 84 receberam metotrexato e 77 placebo, com seguimento médio de $54,7 \pm$
39.2 (DP) semanas. Os hazard ratios (HRs) para primeira e segunda recidivas foram de $0,65(\mathrm{p}=0,04)$ e $0,49(\mathrm{p}=0,02)$, respectivamente, em pacientes que receberam metotrexato em comparação ao placebo. O number needed to treat (número necessário para tratar-NNT) predito foi de 3,6 pacientes [intervalo de confiança 95\% (IC 95\%) 2,2-56,8] para prevenir uma primeira recidiva e 4,7 pacientes (IC 95\% 3,3-21,9) para prevenir uma segunda recidiva em 48 semanas. O uso de metotrexato resultou redução cumulativa de corticóide de $842 \mathrm{mg}$ em 48 semanas ( $\mathrm{p}<0,001)$. A adição de MTX também se associou a maior probabilidade de descontinuação do corticóide maior que 24 semanas (HR 2,84, p = 0,001). $\mathrm{O}$ estudo conclui que o metotrexato deve ser considerado uma opção terapêutica adicional ao corticóide em pacientes com arterite temporal. 
Mazlumzadeh M, Hunder GG, Easley KA, Calamia KT, Matteson EL, Griffing WL, Younge BR, Weyand CM, Goronzy JJ. Treatment of Giant Cell Arteritis Using Induction Therapy With High-Dose Glucocorticoids: A Double-Blind, Placebo-Controlled, Randomized Prospective Clinical Trial (Tratamento de Arterite de Células Gigantes usando terapia de indução com altas doses de corticóide: estudo randomizado, prospectivo, duplo-cego e placebo controlado). Arthritis Rheum 54: 3310-8, 2006. Lowance Center for Human Immunology, Faculdade de Medicina da Universidade Emory, Atlanta, EUA.

Ainda que a maior parte dos pacientes com arterite temporal apresente resposta a corticóide, seu uso por período prolongado sabidamente se associa a efeitos secundários deletérios. Neste ensaio clínico controlado, os autores avaliaram a hipótese de que a administração de doses mais altas de corticóide (pulsoterapia) no início do tratamento permitisse o controle mais rápido da doença, com conseqüente redução da dose e dos efeitos adversos a ela relacionados. Vinte e sete pacientes foram randomizados para receber metil-prednisolona $15 \mathrm{mg} / \mathrm{kg}$ ou solução salina, por via endovenosa, por três dias consecutivos. Na seqüência, todos os pacientes recebiam prednisona $40 \mathrm{mg} /$ dia, com redução progressiva, de acordo com a percepção da atividade da doença. O número de pacientes em remissão ao longo do tempo, a incidência de recidivas, a dose cumulativa de corticóide e os efeitos adversos foram comparados. Em 36 semanas, 10 dos 14 pacientes que receberam a pulsoterapia, mas apenas 2 dos 13 pacientes do grupo-controle, encontravam-se em remissão recebendo prednisona $\leq 5 \mathrm{mg} /$ dia $(\mathrm{p}=0,003)$. Em 78 semanas, 12 pacientes do grupo que recebeu pulsoterapia e 4 pacientes do grupo-controle estavam em remissão com dose de prednisona $\leq 5 \mathrm{mg} /$ dia $(\mathrm{p}=0,006)$. O número de recidivas também foi menor no grupo que recebeu corticóide endovenoso $(21 \mathrm{em} 14$ pacientes versus $37 \mathrm{em} 13$ patientes; $\mathrm{p}=0,028$ ). A dose cumulativa de corticóide em 78 semanas, excluindo-se a dose endovenosa inicial foi de $5.636 \mathrm{mg}$ no grupo que recebeu a pulsoterapia em comparação a $7.860 \mathrm{mg}$ no grupo-controle $(\mathrm{p}=0,001)$. Não existiu diferença na incidência de efeitos adversos. Os autores concluem então que o tratamento inicial da arterite temporal com corticóide endovenoso em dose maior permite redução mais rápida do corticóide com menor dose cumulativa e benefícios em longo prazo, incluindo maior número de pacientes em remissão.

Hoffman GS, Cid MC, Rendt-Zagar KE, Merkel PA, Weyand CM, Stone JH, Salvarani C, Xu W, Visvanathan S, Rahman MU. Infliximab for maintenance of glucocorticosteroid-induced remission of giant cell arteritis: a randomized trial (Infliximabe para manutenção de remissão induzida por corticóide em arterite de células gigantes: um ensaio randomizado). Ann Intern Med 146:621-30, 2007. Do Infliximab-GCA Study Group.

Este estudo procurou avaliar a eficácia de infliximabe como agente anti-TNF em arterite temporal. Quarenta e quatro pacientes com arterite de células gigantes recentemente diagnosticados (até quatro semanas) que entraram em remissão com o uso de corticóide foram randomizados na proporção de $2: 1$ para receberem infliximabe $5 \mathrm{mg} / \mathrm{kg} /$ infusão ou placebo nas semanas $0,2,6$ e a cada 8 semanas. Os desfechos primários eram a proporção de pacientes que se mantinham em remissão na semana 22 e efeitos adversos. Os desfechos secundários foram tempo até a primeira recidiva, biomarcadores de atividade inflamatória da doença (interleucina-6, velocidade de hemossedimentação e proteína $\mathrm{C}$ reativa), dose cumulativa de corticóide e proporção de pacientes que se mantinham em remissão quando a dose de corticóide era reduzida para $\leq 10 \mathrm{mg} /$ dia de prednisona ou equivalente. O estudo foi inicialmente planejado para 54 semanas, mas foi interrompido na $22^{\text {a }}$ semana quando uma análise intermediária mostrou que não existia qualquer sinal de efeito benéfico de infliximabe em comparação ao placebo. A adição de infliximabe ao tratamento não aumentou a proporção de pacientes em remissão na $22^{\text {a }}$ semana $(43 \%$ versus $50 \% ; \mathrm{p}=0,65)$, tão pouco a proporção de pacientes com dose de prednisona $\leq 10 \mathrm{mg} /$ dia $(61 \%$ versus $75 \% ; p=0,31)$. A incidência de infecção foi de $71 \%$ no grupo da droga ativa e $56 \%$ no grupo placebo [diferença de $15 \%$ (intervalo de confiança 95\%) - 14\% a 45\%]. A principal conclusão é que o estudo foi pequeno para fornecer conclusões definitivas, mas é improvável que o infliximabe adicione benefício como tratamento adjuvante nesse contexto clínico - pacientes com diagnóstico recente que responderam prontamente ao corticóide oral. Entretanto, é importante salientar que tal estudo não contemplou a situação específica de pacientes refratários ao corticóide ou outros imunossupressores, pois um eventual resultado positivo nesse subgrupo estaria "diluído" em uma amostra de pacientes com doença menos grave. 